\title{
KEMAMPUAN MENEMUKAN FAKTA DAN OPINI DALAM TEKS PIDATO JOKOWI PADA PEMBUKAAN MUKTMAR KE 33 MELALUI MODEL COLLABORATIVE LEARNING SISWA KELAS IX SMA TAMANSISWA MEDAN
}

\author{
SUHARIYANTI
}

\author{
Jurusan Pendidikan Bahasa dan Sastra Indonesia \\ PPs Universitas Negei Medan \\ Suhariyanti_unimed@yahoo.com
}

\begin{abstract}
Abstrak. Penelitian ini bertujuan untuk mengetahui kemampuan siswa menemukan fakta dan opini dalam teks pidato jokowi pada pembukaan muktamar ke 33 melalui model collaborative learning. Lokasi penelitian dilaksanakan di SMA Tamansiswa Medan yang beralamat di jalan singosari nomor 11. Populasi penelitian ini adalah seluruh siswa kelas XI SMA Tamansiswa Medan yang berjumlah 97 siswa tersebar 4 kelas. Untuk menentukan sampel, peneliti menggunakan teknik random kelas dan terpilih kelas XI IPA-2 yang berjumlah 21 siswa sebagai kelas eksperimen dan XI IPA-1 yang berjumlah 21 siswa sebagai kelas kontrol. Metode dalam penelitian ini menggunakan metode eksperimen. Dalam penelitian ini, peneliti menggunakan instrumen penelitian berupa tes essai yaitu menemukan fakta dan opini dalam teks pidato jokowi pada pembukaan muktamar ke 33. Berdasakan analisis data diperoleh kemampuan menemukan fakta dan opini dalam teks pidato Joko Widodo kelompok eksperimen memperoleh mean 83,80 kategori baik sekali sedangkan kelas kontrol memperoleh mean 71,80 kategori baik. Dari hasil penelitian ini dapat diketahui bahwa hipotesis terbukti, melalui uji t diperoleh $t_{\text {hitung }}>t_{\text {tabel }}$ atau 6,5 $>2,70$.
\end{abstract}

Kata Kunci: Kemampuan menemukan Fakta dan opini, Model Collaborative learning, Teks pidato pembukaan muktamar ke 33.

\section{PENDAHULUAN}

Pembelajaran bahasa Indonesia selain untuk meningkatkan keterampilan berbahasa, juga meningkatkan kemampuan berpikir, mengungkapkan gagasan, perasaan, pendapat, persetujuan, keinginan, penyampaian informasi tentang suatu peristiwa, dan kemampuan memperluas wawasan. Salah satu materi pembelajaran bahasa Indonesia adalah fakta dan opini, tepatnya menemukan fakta dan opini dalam teks pidato Jokowi. Materi menemukan fakta dan opini tampaknya cukup sulit diajarkan dan cenderung membosankan dari pada materi pembelajaran lainnya. Kemampuan yang rendah ini disebabkan oleh beberapa faktor, yaitu faktor internal maupun faktor eksternal. Faktor internal disebabkan oleh pemahaman dan pengetahuan siswa tentang fakta dan opini sangat rendah, 
kurangnya minat siswa dalam pembelajaran fakta dan opini, kurangnya kemampuan siswa dalam pembelajaran fakta dan opini sedangkan faktor eksternal berasal dari kurangnya sarana media yang digunakan oleh guru dan guru masih menggunakan model pembelajaran yang tradisional sehingga siswa merasa jenuh dan bosan pembelajaran menemukan fakta dan opini.

Keterampilan menemukan adalah keterampilan yang sangat penting dalam proses pembelajaran. Siswa diajarkan untuk menemukan hal-hal yang belum mereka ketahui dalam pembelajaran. Siswa juga diajarkan untuk kreatif, inovasi dalam mengungkapkan suatu gagasan atau mengespresikan suatu pendapat, pemikiran, dan perasaan yang dimiliki dalam proses belajar mengajar.

Permasalahan yang dikaji dalam penelitian ini adalah Bagaimana kemampuan siswa menemukan fakta dan opini dalam teks pidato Jokowi melalui model collaborative learning oleh siswa kelas XI SMA Tamansiswa Medan. Bagaimana kemampuan siswa menemukan fakta dan opini dalam teks pidato Jokowi dengan menggunakan model ceramah oleh siswa kelas XI SMA Tamansiswa Medan. Apakah ada perbedaan hasil tes siswa menggunakan model collaborative learning dengan hasil tes menggunakan model ceramah terhadap kemampuan menemukan fakta dan opini dalam teks pidato jokowi oleh siswa kelas XI SMA Tamansiswa Medan.

Tujuan penelitian adalah untuk mengetahui kemampuan siswa menemukan fakta dan opini dalam teks pidato Jokowi melalui model collaborative learning oleh siswa kelas XI SMA Tamansiswa Medan. Untuk mengetahui kemampuan siswa menemukan fakta dan opini dalam teks pidato Jokowi dengan menggunakan model ceramah oleh siswa kelas XI SMA Tamansiswa Medan. Perbedaan hasil tes siswa menggunakan model collaborative learning dengan hasil tes menggunakan model ceramah terhadap kemampuan menemukan fakta dan opini dalam teks pidato jokowi oleh siswa kelas XI SMA Tamansiswa Medan.

Daryanto (2014: 20) "Model pembelajaran kolaborasi (collaboration learning) adalah menempatkan peserta didik dalam kelompok kecil dan memberinya tugas di mana mereka saling membantu untuk menyelesaikan tugas atau pekerjaan kelompok". Dukungan sejawat, keragaman pandangan, pengetahuan dan keahlian sangat membantu mewujudkan belajar kolaboratif. Collaborative learning atau pembelajaran melalui kerja sama menurut smith \& MacGregor (1992) adalah satu istilah untuk suatu jenis pendekatan pendidikan yang meliputi penggabungan karya/usaha intelektual siswa 
atau siswa bersama dengan guru. Biasanya, siswa bekerja dalam 2 atau lebih kelompok, saling mencari pemahaman, penyelesaian atau arti atau membentuk suatu produk/hasil. Latar belakang munculnya pembelajaran kolaboratif dapat menyediakan peluang untuk menuju pada kesuksesan praktik pembelajaran. Sebagai teknologi untuk pembelajaran, pembelajaran kolaboratif melibatkan partisipasi aktif para siswa dan meminimisasi perbedaan-perbedaan antarindividu.

Hosnan (2014:313) langkah-langkah

collaboration learning sebagai berikut.

a. Para siswa dalam kelompok menetapkan tujuan belajar dan membagi tugas sendirisendiri.

b. Semua siswa dalam kelompok membaca, berdiskusi, dan menulis.

c. Kelompok kolaboratif bekerja secara bersinergi,mengidentifikasi,

mendemonstrasikan,meneliti, menganalisis, dan memformulasikan jawaban - jawaban, tugas atau masalah yang ditemukan sendiri.

d. Setelah kelompok kolaboratif menyepakati hasil pemecahan masalah, masing-masing siswa menulis laporan sendiri-sendiri secara lengkap.

e. Guru menunjuk salah satu kelompok secara acak (selanjutnya diupayakan agar semua kelompok dapat giliran ke depan) untuk melakukan presentase hasil diskusi kelompok kolaboratif nya di depan kelas, siswa pada kelompok lain mengamati, mencermati, membandingkan hasil presentasi tersebut dan menganggapi. Kegiatan ini dilakukan selama lebih kurang 20-30 menit.

f. Masing-masing siswa dalam kelompok kolaboratif melakukan elaborasi, inferensi, dan revisi (bila diperlukan) terhadap laporan yang akan dikumpulkan.

g. Laporan masing-masing terhadap tugastugas yang telah dikumpulkan, disusun per kelompok kolaboratif. Laporan siswa dikoreksi, dikomentari, dinilai, dikembalikan pada pertemuan berikutnya, dan didiskusikan.

Djuroto (2005:6) mengatakan, "Fakta adalah kenyataa yang ada sesuai dengan keadaan yang sebenarnya”. Kemudian, menurut SediaWiling Barus (2002 : 27) "Fakta baru dapat disebut berita jika dibuat menjadi kesadaran umum dengan melaporkanya". Suyono (2007:19), "Fakta dapat dibedakan atas dua bagian, yaitu fakta peristiwa dan fakta jumlah". Suyono (2007:2) ciri-ciri fakta sebagai berikut: (1) Sumber fakta dari kejadian, peristiwa, hal objek yang ada disekitar kita. Oleh karena itu, fakta selalu bersifat faktual. (2) 
Kebenaran sesuai dengan kejadian, peristiwa, hal atau objek yang diungkapkan. Artinya selama yang mengungkapkan itu cermat dan bertanggung jawab, fakta pasti ada dan benarbenar terjadi, wujud, pengungkapan, dalam pernyataan.

Djuroto (2005:45)" pendapat adalah opini, merupakan sarana bagi masyarakat untuk mencapai ide atau gagasan, kritik dan saran kepada sistem masyarakat yang merupakan kontrol bagi pelaksanaan pemerintahan". Alwi (2005:989) mengatakan, pendapat adalah pemikiran, pandangan, pendirian. Suyono (2007:95) mengemukakan," pendapat ialah pandangan surat kabar atau reduksi atau pendapat penulis tentang suatu peristiwa ,pemikiran atau pandangan yaitu terjadi atau hidup dalam masyarakat. Menurut Djuroto (2005:78), pendapat dibedakan atas dua, yaitu pendapat belaka dan pendapat terinformasi. (1) Pendapat belaka adalah pendapat yang hanya berdasarkan pemikiran belaka misalnya dugaan perkiraan. Pendapat terinformasi. (2) Pendapat terinformasi adalah pendapat atau gagasan yang berdasarkan pemikiran rasional.

Suyono (2007:18) ciri-ciri pendapat sebagai berikut (1)Isi pendapat merupakan hasil pemahaman dan penilaian seseorang mengenai sesuatu (hal, peristiwa atau kejadian, benda, orang, atau identitas lainnya). (2) Cara pengungkapan pendapat berupa pernyataan (3) Kebenaran pendapat bersifat relative bergantung pada waktu dan tempat, sudut pandang dan bukti-bukti pendukung yang relevan. (4) Menunjukan peristiwa yang belum terjadi dan kebenaranya bersifat subyektif.

\section{TEKS PIDATO JOKOWI PEMBUKAAN MUKTAMAR 33}

\section{Assalamualaikum Warahmatullahi}

\section{Wabarakatuh.}

Yang saya hormati para alim ulama' Yang saya hormati ketua umum dan keluarga besar serta jajaran pengurus besar Nahdlatul Ulama

Hadirin Muktamirin Muktamirat yang berbahagia

Marilah kita bersyukur kehadirat Allah SWT karena atas rahmat dan karunianya kita dapat hadir pembukaan Muktamar ke-33 Nahdlatul Ulama di Kota Jombang, Jawa Timur. Shalawat dan salam kita haturkan untuk junjungan kita nabi besar Muhammad SAW beserta keluarganya para sahabat serta para pengikutnya hingga akhir zaman.

Hadirin sekalian yang saya muliakan 
Penuh rasa gembira, saya menyambut dimulainya Muktamar ke-33 jamiyyah Nahdlatul Ulama malam ini sebagai salah satu jamiyyah diniyyah Islamiyah terbesar di Indonesia, Nahdlatul Ulama telah memberikan kontribusi besar untuk menjaga Indonesia dan tetap menjadi Indonesia. Sejarah mencatat, sejak didirikannya pada tahun 1926 tokoh-tokoh Nahdlatul Ulama turut membidani lahirnya Negara Kesatuan Republik Indonesia, dan menjaga dari berbagai bentuk ancaman. Oleh karena itu, tidak diragukan lagi jika Nahdlatul Ulama senantiasa menjadi garda terdepan dalam menjaga NKRI dan Pancasila. Dan ini, menjadi bukti keteguhan sikap Nahdlatul Ulama dalam menjunjung semangat kebangsaan, menjunjung semangat menegakkan keindonesiaan, menjunjung semangat menghargai kebhinekaan. Saya mengapresiasi tema besar yang dipilih Nahdlatul Ulama dalam muktamar kali ini yakni 'Meneguhkan Islam Nusantara untuk Peradaban Indonesia dan Dunia'. Saya mendorong agar tema ini dimaknai secara positif karena tema ini menunjukkan bahwa Nahdlatul Ulama dan umat Islam Indonesia memiliki posisi yang setrategis bukan hanya dalam membentuk peradaban bangsa, tetapi bisa menjadi inspirasi peradaban dunia.

Sebagai role model pengusung Islam yang rahmatan lil 'alamin yang memberikan kedamaian dan manfaat bagi alam semesta, tema itu juga cermin keteguhan warga nahdliyin untuk menjadikan Islam sebagai pijakan terciptanya masyarakat unggulan. Yakni, masyarakat yang menjadikan agama sebagai sumber kemajuan, sebagai sumber keadilan, dan sebagai sumber kedamaian. Nahdlatul ulama memiliki peran yang sangat penting dalam menampilkan serta meneguhkan wajah Islam yang moderat. Untuk itu, kita mengucapkan terima kasih kepada Hadratus Syaik KH Hasyim Asy’ari yang telah menanamkan benih unggul sikap moderat bagi warga Nahdliyin di mana pun berada.

Muktamirin Muktamirat Yang Saya Hormati Senin lalu (27/7), saya menerima kunjungan Perdana Menteri Inggris, David Cameron, di Istana Negara Jakarta. Dalam kunjungannya itu beliau tertarik mempelajari sejarah perkembangan Islam di Negara kita, Islam yang demokratis, Islam yang toleran, dan Islam yang maju. Beliau bahkan ingin mengetahui lebih banyak mengenai peran organisasi kemasyarakatan Islam di Indonesia dalam menghadapi tantangan radikalisme global. Beliau bertanya sangat detail sekali, Nahdlatul Ulama ditanyakan, Muhammadiyah juga ditanyakan secara detail sehingga penjelasannya pun kita sampaikan secara detail. Beliau sangat menghargai apa yang terjadi di Indonesia karena di luar Indonesia semuanya 
sekarang ini pada posisi yang tidak baik. Karena itulah saya menaruh harapan pada Nahdlatul Ulama sebagai salah satu, organisasi Islam terbesar di Indonesia untuk mampu menjadi jembatan peradaban. Jembatan bagi perbedaan faham keagamaan, tetapi juga menjadi peradaban antar bangsa dalam wujud nyata Islam sebagai rahmatan lil 'alamin.

Sebagai jamiyyah diniyyah Islamiyyah yang sejak kelahirannya mengedepankan nilainilai Islam moderat, saya berharap Nahdlatul Ulama dapat meningkatkan kerja sama dengan berbagai kalangan untuk membangun tatanan dunia yang berkeadilan. Khususnya, nahdlatul ulama dalam mengentaskan kemiskinan, keterbelakangan, dan ketimpangan yang merupakan akar dari bentuk-bentuk terorisme dan radikalisme. Dengan sikap Nahdlatul Ulama yang mengutamakan solidaritas kemanusiaan, ukuwah basyariyah, maka warga Nahdliyin berperan besar dalam membangun peradaban antar bangsa yang semakin terbuka, demokratis dan berkeadilan. Dengan cara itu Indonesia sebagai negeri dengan jumlah penduduk muslim terbesar di dunia akan selalu dikenang menjadi rujukan dunia. Para Ulama dan Hadirin Sekalian Yang Saya Hormati, sebelum mengakhiri pidato ini, ijinkan saya atas nama Negara dan pemerintah menyampaikan ucapan terima kasih kepada segenap keluarga besar Nahdlatul Ulama berperan besar dalam menjaga keindonesiaan dan kebhinekaan. Kejadian rusuh di Tolikara, Papua, pada saat Idul Fitri 1 Syawal 1436 Hijriyah harus menjadi pelajaran berharga, harus menjadi koreksi bagi kita untuk senantiasa membangun komunikasi yang baik antar umat beragama. Toleransi yang telah dibangun sejak lama di seluruh Nusantara tidak boleh ternodai karena sikap segelintir orang. Mari kita teguhkan posisi Nahdlatul Ulama sebagai jamiyyah diniyyah Islamiyyah yang moderat, mari kita tingkatkan dialog, sikap toleran, dan komunikasi yang baik dalam kehidupan keagamaan, dengan karakter Nahdlatul Ulama yang sering menggiatkan semangat toleransi, kebersamaan dan musyawarah untuk mufakat, saya berkeyakinan bahwa Muktamar ini akan berjalan dengan lancar, damai, sejuk dan sukses.Dan sebagai sedikit tambahan, sejak saya menjadi presiden gelar pahlawan nasional pertama kali akan saya anugerahkan kepada tokoh NU dari Jombang yaitu KH. Abdul Wahab Chasbullah.

Demikian yang bisa saya sampaikan terimakasih.Wassalamu'alaikum

warohmatullahi wabarakatuh.

Penelitian yang relevan dalam penelitian ini dilakukan oleh Rina Sartika, dkk. Kemampuan menemukan fakta dan opini 
melalui kegiatan membaca intensif siswa kelas X SMK Padang.

Ni Putu Sri Darmayanti ,Penerapan model inkuiri dalam pembelajaran fakta dan opini pada artikel dikelas X SMK N1 sukasda.

Drs. Syahnan Daulay, M.Pd, Pengaruh Model Pembelajaran Kolaboratif (Collaborative Learning) Terhadap Kemampuan Menulis Teks Eksposisi Siswa Kelas X SMA Negeri 1 Balige Tahun Pembelajaran 2013/2014.

Berdasarkan uraian diatas peneliti tertarik mengadakan penelitian berjudul Kemampuan Menemukan Fakta dan Opini dalam Teks Pidato Jokowi Pada Pembukaan Muktamar ke 33 Melalui Model Collaborative Learning Siswa Kelas IX SMA Tamansiswa Medan.

\section{METODE PENELITIAN}

Penelitian ini dilakukan di SMA Tamansiswa, di Jalan Singosari No.11 Medan. Populasi dalam penelitian ini adalah seluruh kelas XI SMA Tamansiswa Medan yang berjumlah 95 siswa yang terdiri dari 4 kelas yaitu XI IPA 1 berjumlah 21, XI IPA 2 berjumlah 21, XI IPS 1 berjumlah 28, XI IPS 2 berjumlah 28 .

Pengambilan sampel digunakan random atau random sampling ditentukan kelas XI IPA 2 berjumlah 19 siswa sebagai kelas eksperimen, dan kelas XI IPA 1 berjumlah 21 siswa sebagai kelas kontrol. Pada penelitian ini menggunakan metode eksperimen dengan menggunakan Posttest-only control design. Metode eksperimen digunakan dengan maksud melihat akibat dari suatu perlakuan. Instrumen yang digunakan untuk mengumpulkan data dalam penelitian ini adalah tes essai. Tes essai adalah alat ukur yang digunakan untuk mengukur aspek-aspek dalam bentuk angka. Tes essai teks pidato jowoki dibagi persiswa atau sebanyak jumlah siswa masing - masing siswa mendapat teks pidato.

\section{HASIL PENELITIAN DAN PEMBAHASAN}

Kemampuan siswa menemukan fakta dan opini dalam teks pidato jokowi pada pembukaan muktamar ke 33 melalui model kolaboratif (Collaborative Learning) memiliki pengaruh yang signifikan menunjukkan nilai rata-rata 83,80 Diketahui bahwa hasil post test menemukan fakta dan opini dengan menggunakan model pembelajaran kolaboratif (Collaborative Learning) siswa yang memperoleh skor tertinggi yaitu 96 sebanyak 5 siswa atau 23,80\%, skor 88 sebanyak 6 siswa atau $28,57 \%$, skor 84 sebanyak 2 siswa atau 9,52\%, skor 76 sebanyak 3 siswa atau 14,28\%, skor 72 sebanyak 4 siswa atau 19,04\%, skor 68 sebanyak 1 siswa atau $4,76 \%$. 


\section{Aspek Penilaian Menemukan Fakta dan Opini}

\begin{tabular}{|l|l|c|}
\hline NO & ASPEK PENILAIAN (FAKTA) & SKOR \\
\hline 1. & Siswa mampu menemukan 13 & $\mathbf{1 3}$ \\
\hline 2 & Siswa mampu menemukan 12 & $\mathbf{1 2}$ \\
\hline 3 & Siswa mampu menemukan 11 & $\mathbf{1 1}$ \\
\hline 4 & Siswa mampu menemukan 10 & $\mathbf{1 0}$ \\
\hline 5 & Siswa mampu menemukan 9 & $\mathbf{9}$ \\
\hline 6 & Siswa mampu menemukan 8 & $\mathbf{8}$ \\
\hline 7 & Siswa mampu menemukan 7 & $\mathbf{7}$ \\
\hline 8 & Siswa mampu menemukan 6 & $\mathbf{6}$ \\
\hline 9 & Siswa mampu menemukan 5 & $\mathbf{5}$ \\
\hline 10 & Siswa mampu menemukan 4 & $\mathbf{4}$ \\
\hline 11 & Siswa mampu menemukan 3 & $\mathbf{3}$ \\
\hline 12 & Siswa mampu menemukan 2 & $\mathbf{2}$ \\
\hline 13 & Siswa mampu menemukan 1 & \\
\hline
\end{tabular}

\begin{tabular}{|l|l|c|}
\hline NO & ASPEK PENILAIAN (OPINI) & SKOR \\
\hline 1. & Siswa mampu menemukan 12 & $\mathbf{1 2}$ \\
\hline 2 & Siswa mampu menemukan 11 & $\mathbf{1 1}$ \\
\hline 3 & Siswa mampu menemukan 10 & $\mathbf{1 0}$ \\
\hline 4 & Siswa mampu menemukan 9 & $\mathbf{9}$ \\
\hline 5 & Siswa mampu menemukan 8 & $\mathbf{8}$ \\
\hline
\end{tabular}

\begin{tabular}{|l|l|c|}
\hline 6 & Siswa mampu menemukan 7 & $\mathbf{7}$ \\
\hline 7 & Siswa mampu menemukan 6 & $\mathbf{6}$ \\
\hline 8 & Siswa mampu menemukan 5 & $\mathbf{5}$ \\
\hline 9 & Siswa mampu menemukan 4 & $\mathbf{4}$ \\
\hline 10 & Siswa mampu menemukan 3 & $\mathbf{3}$ \\
\hline 11 & Siswa mampu menemukan 2 & $\mathbf{2}$ \\
\hline 12 & Siswa mampu menemukan 1 & $\mathbf{1}$ \\
\hline
\end{tabular}

NilaiAkhir : $\frac{\text { Perolehan x Skor ideal }}{\text { SkorMaksimum }}(100)=\ldots$

2. Distribusi frekuensi menemukan fakta dan opini dalam teks pidato jokowi menggunakan collaborative learning

\begin{tabular}{|c|c|c|c|}
\hline No & Skor & Frekuensi & \% \\
\hline 1 & 68 & 1 & $4,76 \%$ \\
\hline 2 & 72 & 4 & $19,04 \%$ \\
\hline 3 & 76 & 3 & $14,28 \%$ \\
\hline 4 & 84 & 2 & $9,52 \%$ \\
\hline 5 & 88 & 6 & $28,57 \%$ \\
\hline 6 & 96 & 5 & $23,80 \%$ \\
\hline \multicolumn{2}{|c|}{$\sum$} & $\mathbf{2 1}$ & $\mathbf{1 0 0 \%}$ \\
\hline
\end{tabular}

Siswa yang memperoleh skor tertinggi yaitu 96 sebanyak 5 siswa atau 23,80\%, skor 88 sebanyak 6 siswa atau 28,57\%, skor 84 sebanyak 2 siswa atau 9,52\%, skor 76 sebanyak 3 siswa atau 14,28\%, skor 72 sebanyak 4 siswa atau 19,04\%, skor 68 sebanyak 1 siswa atau $4,76 \%$. 
3. Distribusi frekuensi menemukan fakta dan opini dalam teks pidato Jokowi menggunakan model ceramah

\begin{tabular}{|c|c|c|c|}
\hline No & Skor & Frekuensi & \% \\
\hline 1 & 56 & 3 & 14,28 \\
\hline 2 & 60 & 4 & 19,04 \\
\hline 3 & 64 & 2 & 9,52 \\
\hline 4 & 72 & 4 & 19,04 \\
\hline 5 & 84 & 5 & 23,80 \\
\hline 6 & 88 & 3 & 14,28 \\
\hline \multicolumn{2}{|c|}{$\sum$} & $\mathbf{2 1}$ & $\mathbf{1 0 0 \%}$ \\
\hline
\end{tabular}

Siswa yang memperoleh skor tertinggi yaitu 88 sebanyak 3 siswa atau 14,28\%, skor 84 sebanyak 5 siswa atau $23,80 \%$, skor 72 sebanyak 4 siswa atau 19,04\%, skor 64 sebanyak 3 siswa atau 9,52\%, skor 60 sebanyak 4 siswa atau 19,04\%, skor 56 sebanyak 3 siswa atau $14,28 \%$.

Hasil pengujian normalitas dan homogenitas dari kedua kelompok pembelajaran menunjukan persyaratan analisis pada penelitian ini berdistribusi normal dan bervarians kelompok-kelompok sampel adalah homogen.

Nilai thitung diperoleh, selanjutnya dibandingkan dengan nilai $t_{\text {tabel }}$ pada taraf signifikan $\alpha=0,05$ dengan $\mathrm{dk}=\mathrm{N}_{1}+\mathrm{N}_{2}-2=40$ didapat $t_{\text {tabel }}=2,70$. Karena nilai $t_{\text {hitung }}>t_{\text {tabel }}$ yaitu $6,5>2,70$. Hal ini berarti kemampuan menemukan fakta dan opini menggunakan model pembelajaran collaborative learning lebih berpengaruh dibandingkan dengan menggunakan model pembelajaran ceramah dalam meningkatkan kemampuan menemuka fakta dan opini pada teks pidato Jokowi oleh siswa kelas XI SMA Tamansiswa Medan.

Oleh karena itu $t_{\text {hitung }}>t_{\text {tabel }}$ maka disimpulkan terdapat pengaruh yang signifikan penggunaan model pembelajaran collaborative learning terhadap kemampuan menemuka fakta dan opini dalam teks pidato Jokowi oleh siswa kelas XI SMA Tamansiswa Medan.

Dengan demikian hipotesis alternatif $\left(\mathrm{H}_{\mathrm{a}}\right)$ dinyatakan terbukti kebenarannya, dan diterima.

\section{PENUTUP}

\section{SIMPULAN}

Berdasarkan hasil pembahasan yang telah diuraikan maka dapat ditarik kesimpulan sebagai berikut, hasil kemampuan menemukan fakta dan opini dalam teks pidato Jokowi pada pembukaan muktamar ke 33 melalui model collaborative learning di SMA Tamansiswa Medan jalan singosari No. 11 dinyatakan baik sekali karena mendapatkan nilai rata-rata 83,80. Hasil tes menggunakan model ceramah mendapat nilai cukup karena mendapat nilai rata-rata 71.80. Hasil penelitian menggunakan model collaborative learning dapat meningkatkan pemahaman siswa tentang apa 
yang dipelajari sehingga diharapkan mereka dapat menerapkan dalam kondisi nyata pada kehidupan sehari-hari. Jadi Model pembelajaran Collaborative Learning memberikan siswa pemahaman untuk berkolaborasi, mampu berpikir dan bertanggung jawab dan menumbuhkan kreativitas dalam proses pembelajaran.

\section{SARAN}

Meningkatkan hasil belajar bahasa Indonesia siswa, hendaknya guru dapat memberikan latihan-latihan menemukan fakta dan opini. Penggunaan buku bervariasi akan meningkatkan pemahaman serta kreativitas siswa dalam menemukan fakta dan opini. Kepada kepala SMA Tamansiswa Medan, agar mengupayakan pengadaan buku-buku yang menyangkut tentang pembelajaran bahasa Indonesia, khususnya dalam pembelajaran Fakta dan opini.

\section{DAFTAR PUSTAKA}

Arikunto, Suharsimi. 2010. Prosedur Penelitian (Satuan Pendekatan Praktik). Yogyakarta: Rineka Cipta.

Alwi, Hasan. 2005. Kamus Besar Bahasa Indonesia.Jakarta : Balai Pustaka.

Budyatna, Muhammad. 2012. Jurnalistik Teori \& Praktik, Bandung : PT Remaja Rosdakarya .

Daryanto. 2014. Pendekatan Pembelajaran Saintifik Kurikulum 2013. Yogyakarta: Gava Media.
Depag, RI. 2005. Al-Qur'an dan Terjemahannya. Semarang: Asy Syifa.

Djuroto,Fotak.2005. Menulis Artikel dan Karya Ilmiah.Bandung : Remaja Doliarya.

Hosnan, M. 2014. Pendekatan Saintifik dan Kontekstual dalam Pembelajaran Abad 21.Galia Indonesia IKAPI, Bogor.

Hamiyah, Nur dan Jauhar, Muhammad. 2014. Strategi Belajar Mengajar Di KelasJakarta: Prestasi Pustaka.

Istarani.2011. 58 Pembelajaran Inovatif.Medan : Media Persada.

Kamus Besar Bahasa Indonesia. 2002. Jakarta : Balai Pustaka .

Ngalimun. 2013. Strategi dan Model Pembelajaran. Yogyakarta : Aswaja Pressindo.

Ruseffendi. 2005. Model Pembelajaran Konvensional. Medan: Media persada.

Suyono. 2007. Pengantar Jurnalistik. Bandung. Nuansa Cendika.

Sudijono, Anas. 2011. Pengantar Evaluasi Pendidikan.Jakarta : Rajawali Grafindo Persada.

Sudjana. 2002. Metode Statistika.Bandung: Penertbit Tarsito.

Sugiyono. 2010. Metode penelitian Pendidikan. Pendekatan Kuantitatif, Kualitatif, dan $R$ \& I. Bandung: Alfabeta.

Sudijono , Anas . 2008. Pengantar Statistik Pendidikan .Jakarta : PT Raja Grafindo Persada.

Willing , Sedia Barus. 2010. Jurnalistik Petunjuk Tehnik Menulis Berita. Erlangga. 
